\title{
Verb syncopation and predicate raising in Mauritian Creole ${ }^{1}$
}

\author{
PIETER A. M. SEUREN
}

\section{Abstract}

Mauritian Creole (MC) has a morphophonemic rule of verb syncopation (VS), whereby the full form of certain verbs is shortened by the dropping of the final vowel or otherwise. The application conditions for this rule have so far not been established unequivocally. This paper provides an analysis which allows for one simple condition on the application of VS: VS applies whenever the verb in question (provided it belongs to the class of syncopators) is followed by further material of its own VP, except when that material is itself an embedded VP or $S$. In order to uphold this principle it is necessary to posit that $M C$ has a cyclic rule of predicate raising $(P R)$, which is induced, on some $S_{0}$ cycle with a complement-taking $V_{0}$, by that $V_{o}$, provided $V_{o}$ is marked for $P R$ in the lexicon and other, structural, conditions are met as well, and which raises the $V_{1}$ of the complement $S_{1}$, attaching it to the right of $V_{o}$ into one complex $V$ island directly under $S_{o}$. It will then be clear that verbs that induce PR will be subject to VS when they are followed, within the same VP, and in fact within the same $V$ island, by the raised $V$. On the other hand, complement-taking verbs that do not induce $P R$ will not be subject to $V S$ when they are followed by their embedded VP or S. PR thus helps to keep the condition for VS simple. Yet it is not the case that when a verb is lexically marked for $P R$ it will always automatically induce $P R$. MC has a curious (though not unparallelled) condition on the actual application of PR: whenever the normal SVO order of the sentential constituents runs the risk of being disturbed as a result of $P R, P R$ is replaced by the rule of subject raising (SR), which guarantees the canonical SVO order. It is conjectured that this curious condition is a consequence of a general creole phenomenon, the tendency to maximize semantic transparency. Lexically $P R$ is a very convenient rule since it creates $V$ islands, which easily acquire separate lexical status, but its syntactic consequences run counter to the principle of semantic transparency. MC seems to have struck some balance between the pros and cons of PR. The 
analysis thus supports ecologism at the expense of strict formalism in linguistic analysis.

\section{Verb syncopation}

Verb syncopation, or VS, is the name we give to the phenomenon, commented upon by all authors on Mauritian Creole (MC), that most MC verbs shed their final vowel, almost always $-e$, in certain environments. Most other French-based creoles also drop the final vowel of at least some verb forms, but the conditions differ considerably (Stein 1984: 73-74; Baker and Corne 1982: 64-78). We shall concentrate here on the form of VS that occurs in MC (and almost identically in Seselwa, MC's offspring in the Seychelles), but not in any other French-based creole.

Not all MC verbs are subject to VS. Verbs not ending in - $e$ are not syncopators, except vini 'come' and sorti 'go out, leave'. Verbs ending in consonant $+y$ or $w+e$, such as abitye 'be used to', zwe 'play', do not take VS, except, for some speakers, when the preceding vowel is nasalized: they apparently analyze this as vowel plus the consonant $n$. But we do have, for example, tuye/tuy 'kill', riye/riy 'laugh', where there is no consonant preceding the semivowel. Consonant clusters before the final vowel tend to block VS, though this is not always the case. Thus, aste 'buy', aksepte 'accept', môtre 'show' do not take VS, nor does ule 'want'. For some verbs VS does not just result in the loss of the final vowel, but other morphophonemic changes occur as well: tôbe/tom 'fall', râtre/rât 'enter', vâde/van 'sell', tâde/tan 'hear, dimâde/diman 'ask', reste/res 'live, stay', etc. The verb ete 'be' has the null form ' $\emptyset$ ' as its syncopated variant. Reduplication verbs with $\mathrm{V}_{1}$ syncopated, as in mars-marse 'walk casually, stroll', fin-fini 'finish once and for all', koz-koze 'talk casually, chat' take VS; if $\mathrm{V}_{1}$ is not syncopated, as in marse-marse 'walk for a long time', koze-koze 'talk for a long time', they do not take VS.

Baissac (1880) repeatedly formulates the following rule: when a verb is followed by an argument term, final $-e$, sometimes final $-i$, is dropped. Taking into account possible differences that may have arisen between 1880 and now (see Corne, in Baker and Corne 1982: 70, 72), this rule is in principle, but not in details, correct. The correct formulation of the conditions under which VS applies has so far not been provided.

Corne (Baker and Corne 1982: 49) gives a presumably complete list of the relevant publications up to the date of his writing and then comments, 'This relatively impressive outpouring of ink does not mean, however, that the matter is by any means clearly understood.' Corne's own proposal (1980: 114) is that VS 'applies only when the subject is the Agent', his condition for the rule being one, generally, of 'action'. Although Corne is at pains (Corne 1980: 112-114) to define this semantic notion of 'action' 
in terms of both semantic features and subject-predicate structures, he is quickly forced to water down his criterion. Having said (1980: 112) that 'Action predicates have an Agent as their subject (since that is how they are defined)', he hits on cases where the predicate is not one of action, such as the following two Seselwa sentences (Seselwa is entirely similar to $\mathrm{MC}$ in this respect):

Here, the syncopated forms are used: vin instead of the full vini and gagn instead of gagne. As regards (1a), Corne observes (Baker and Corne 1982: 53-54),

Note that vin(i) means not only 'become', but also 'come'. This is not a case of homonymy, and the lexeme does not have two meanings in IdeFC [that is, MC and Seselwa], but merely in the English (or French) glosses, and so again agentivity explains the application of $<\mathrm{VS}>$ in mô pu vin ris above. I think that the claim made here, that $<$ VS $>$ signals Action, is an accurate one.

One may wonder How exactly the alleged nonhomonymity of vini turns this clearly nonagentive sentence into an agentive one, especially since the sentence as a whole is a prototype of a nonagentive sentence. Then, surprisingly, for sentence (1b), Corne appeals to its alleged overall agentive character. His comment (1980: 114) is, 'There is co-reference between the subject (Agent) $i$ and the (indirect object) pronoun $l i$ " himself"; this co-reference (or reflexivity) produces, for the sentence as a whole, a Patient reading for the subject, but its basic agentive nature is clear.' Not so, one fears, for most readers. Corne (Baker and Corne 1982: 53) provides some further comment: 'In this example ... there is coreference, or reflexivity, between the agentive subject $i$ and the dative pronoun $l i$; this explains the reading of this sentence, whereby we understand that the subject has some degree of responsibility for the shock he receives.' The element of responsibility is recognizable for ( $1 \mathrm{~b})$ : it is due to the ethical dative $l i$. But this cannot be held responsible for the alleged 'action' character of $(1 \mathrm{~b})$, since VS would have applied with equal force if $l i$ had not been there and the sentence had thus lost its last action straw. In any case, as long as the explanatory mechanisms invoked by Corne are not made both testable and explicit, this machinery is more magic than anything else. One is inclined to conclude that some more ink will have to be poured out. 
So let us have a fresh look at the question. Some elementary data will be useful:

(2) a. Mo fin mâze (*mâz).

I Perf. eat

'I have eaten.'

b. Mo fin mâz diri-la (*mâze).

I Perf. eat rice-the

'I have eaten the rice'

(3) a. To kôtâ mâze (*mâz).

you like eat

'You like to eat.'

b. To kôtâ mâz diri (*mâze).

you like eat rice

'You like to eat rice.'

(4) a. Zwazo sâte boner (*?sât) (Virahsawmy 1967: 66). ${ }^{2}$

bird sing early

'Birds sing early.'

b. Li fin mâz boner zordi (*?mâze) (Virahsawmy 1967: 65).

he Perf. eat early today

'He has eaten early today.'

(5) a. Li pu vini dimê (*?vin) (Virahsawmy 1967: 98).

he Fut. come tomorrow

'He will come tomorrow.'

b. Boffam-la fin vin tar lakaz (*?vini) (Baker 1972: 149). woman-the Perf. come late home

'The woman has come home late.'

(6) a. Li vini rarmâ (*?vin) (Virahsawmy 1967: 98).

he come rarely

'He rarely comes by.'

b. Bômatê mo ti lev tar (*?leve) (Baissac 1880: 6).

Morning I Perf. get up late

'This morning I got up late.'

It appears from these sentences that VS operates when a nominal argument term follows the verb, just as Baissac said, whether the verb is finite or infinite. This argument term need not be a direct object; it may also be an indirect object or a measure phrase:

(7) a. Nuti galup en mil (*galupe) (Virahsawmy 1967: 65). we Past run one mile

'We ran one mile.' 
b. Sizi fin âvoy so fami en kart (*âvoye) (Baker 1972: 105). Suzy Perf. send her family a card 'Suzy has sent her folks a card.'

Note, however, that VS is inoperative when a subject follows the verb:
a. Ti vini bonom-la? (*vin).
Past come man-the
'Did the man come?'
b. Kâ ti vini bonom-la? (*vin).
when Past come man-the
'When did the man come?'

With adverbials VS sometimes does and sometimes does not apply. This correlates with their semantic function: when an adverbial functions semantically as a sentential operator, VS does not apply, but when it modifies or specifies the preceding verb, VS does apply. Thus, one sees that in (4)-(6) VS does not apply in the (a) sentences, but it does in the (b) sentences. (4a) says that the singing of birds takes place early in the morning, but in (4b) the subject has eaten early, which is something one does from time to time. Analogously in (5a)-(5b) and (6a)-(6b). In all these sentences the use of the full form where the shorter form is given, or vice versa, does not lead to ungrammaticality but rather to a pragmatically less appropriate semantically different reading. One might say that in the (b) cases, the time adverbial is used more like a manner adverbial.

Manner adverbials clearly induce VS:
a. Tôtô ti vin dâ loto (*vini). uncle Past come by car
'Uncle came by car.'

b. Li mars kumâ en torti (*marse) (Virahsawmy 1967: 100). he walk like a tortoise 'He walks like a tortoise.'

c. Li mars dusmâ (*marse).

he walk slowly 'He walks slowly.'

Adverbials of place may induce VS, depending on their semantic function. If a place adverbial is a further specification of a verb that semantically implies the category 'place' as in the sentences of (10), the tendency is for VS to apply. But if a place adverbial functions as a semantic operator taking the whole proposition as its scope, VS tends not to apply and the 
full form appears, as in (11):

(10) a. Nufin mars dâ simê progre (Virahsawmy, ZM). we Perf. walk in road progress

'We have taken the road of progress.'

b. Mo ti pe asiz divâ mo laport (Baker 1972: 107)

I Past Cont. sit before my door

'I was sitting in front of my door.'

c. Mo papa pe al laba (Virahsawmy 1967: 101).

My dad Cont. go there

'My dad is going there.'

d. Mo tom dâ dilo (Baissac 1880: 42).

I fall in water

'I fall into the water.'

e. Zot pa res isi.

they not live here

'They don't live here.'

(11) a. Nu fin marse dâ simê progre.

we Perf. walk in road progress

'We have walked in the road of progress.'

b. Mo pa ule mâze dâ simê.

I not want eat in street

'I don't want to eat in the street.'

The nonadverbial data clearly suggest that VS is bound up with the VP constituent: the rule seems to be that VS applies when it is followed by further material belonging to the VP to which the verb in question belongs. This is clearly suggested by (2), (3), (7), and (8) above, and also by (1), which shows, moreover, by its (1a), that predicate nominals are likewise treated as belonging to the VP, entirely in agreement with accepted linguistic wisdom. It is not too difficult to extend this generalization to the adverbial cases, since it is well known that adverbials tend to waver between being inside or outside the VP, with concomitant nuances of semantic difference. ${ }^{3}$ We can thus formulate, as a first generalization, the following condition on the application of VS:

(12) VS applies when the verb is a syncopator and is not VP-final.

VS is best considered to apply postcyclically, and clearly after WH fronting, as appears from the following cases:

(13) a. $\mathrm{Ki}$ to ti les isi? ([*]lese).

what you Past leave here

'What did you leave here?' 
b. $\mathrm{Ki}$ to ti mâze? (*mâz).

what you Past eat

'What did you eat?'

c. Pwasô ki to pe frikase-la pa bô (*frikas).

fish that you Cont. stew-the not good

'The fish that you are stewing is not good.'4

In (13a) the syncopated form is used, due to the place adverbial isi 'here' immediately following the verb after WH movement (compare [10e] above). That the application of VS in (13a) is not due to the WH element $k i$ having been moved away from the position just after les, that is, to some 'trace' left behind as a result of WH fronting (as the theory of 'government and binding', and its predecessors since about 1970, have it) appears from cases like (13b), where the full verb form is required, due to it being VP-final. Compare also (19a) and (19c) below, where the full copula form ete is used, given the immediately following time adverbial. The fact that a place adverbial, as in (19a), or a manner adverbial, as in (19c), has been moved away by WH fronting apparently makes a difference: if it did not, we would have expected the syncopated copula form, that is, $\emptyset$. It is obvious that, whatever their status in the theory of grammar, traces have no role to play here.

So far so good. There are, however, a few complications. One complication, to which I have devoted considerable attention while collecting and evaluating my data, seems to arise in cases where there is an opposition, in the combination of verb and object, between a 'set collocation' reading and a reading where the combination is considered free and original. When such an opposition is felt to exist, VS tends not to apply for the free reading. One has the impression that nonapplication of VS is used as a means to mark the fact that the 'fixed collocation' reading is not intended. The difference between the two readings is akin to what is observed in English for expressions like keep tabs on, take care of, take umbrage at, which differ from 'original' combination in various ways as regards their syntactic behavior. (Thus, the passive pattern as found in, for example, She was taken care of is impossible with 'free' objects.) This distinction seems to provide the explanation for the fact that both (14a) and (14b) are good MC, though with different meanings:

(14) a. U pa gagne frè. laba.

you not suffer cold there

'You don't suffer from cold there.'

b. U pa gagn fre.

you not suffer cold

'You aren't cold.' 
I noticed sentence (14a) as it was used in ordinary conversation by a native speaker who is careful and conscious in her use of $\mathrm{MC}$, while she was commenting on the climatic conditions in some country that was being shown on TV. When I pointed out to her that she had produced that sentence and asked her if (14b) would also be good MC, she answered immediately that both were correct, but that there was a difference in meaning, which, however, she found it difficult to make explicit. Others present then began to take part in the discussion, and the upshot was that (14a) is more likely to be a generic statement (with the impersonal 'you'), while (14b) would be said of a specific person having or not having the sensation of being cold. If this is correct, we may surmise that there may, in some cases, be a gradience in the applicability condition of VS: VS signals A CLOSE LINK between the verb and what follows it; when the closeness is subject to degrees, VS signals the closest possible link. It must be added that cases like (14a) are extremely rare, and on the whole clearly anomalous. ${ }^{5}$

A further complication, but hardly as troublesome, is brought about by the fact that most writers make exception for passives in the application of VS. MC has a nonmorphological passive, like many other creole languages, but, unlike most other creoles, it also has a completely developed agent phrase, though the language has not yet settled on one definite preposition: the prepositions used are ar, ek, or avek 'with', 'to'. Baissac (1880: 41-42) states categorically that VS does not apply to passive verbs (he uses the now antiquated preposition $a v$ for the agent phrase):

(15) Tu lanwi mo disâ ti mâze av pinez. all night my blood Past eat with louse

'All night my blood was eaten by lice.'

However, agent phrases are in all likelihood not part of VP, so that the full verb form is to be expected anyway. Baissac's sentence (15) thus constitutes no evidence. Better evidence is provided by Corne (Baker and Corne 1982: 69), who gives the modern MC passive sentence:

Latet torti fin ramas âba lakok.

head tortoise Perf. pull in below shell

'Tortoise's head is pulled in underneath his shell.'

This suggests that VS applies normally to passives. This suggestion is reinforced by the observation that the following sentence proved acceptable:

(17) Sa fin esplik mwa.

that Perf. explain me

'That has been explained to me.' 
It looks as though we may conclude that VS applies normally with passives, although it does not often have the opportunity to show that it does.

We are, however, not yet out of trouble. When the subject of a finite object clause has been lifted into the higher clause, as in ${ }^{6}$

\section{(18) To truve Kapitèn kimanyer li onet (*truv) (Virahsawmy, ZM) you see Captain how he honest \\ 'You see how honest the Captain is.'}

VS does not apply. (Note that this lifting is quite different from cyclic subject raising as discussed below.) Apparently, VS is sensitive to whether or not the following constituent falls within the argument structure of the verb. (We shall see in a moment that the relevant argument structure is either original, that is, as specified in the lexicon, or derived, that is, resulting from predicate raising.) In (18) Kapitèn is not the object of truve (just as ánthropo in note 6 is not the object of thélo): it is the subject of onet, but has been lifted out of its clause to become a quasi object to truve. We can express this by letting the rule that moves Kapitèn out of its clause operate after VS.

Some comment is in order about the copula verb in MC. MC shares with many creole and noncreole languages the feature of copula deletion under certain conditions, and copula retention otherwise. ${ }^{7}$ In MC the main condition seems to link up directly with VS. As has been indicated above, the full form of the MC copula is ete. Under the same conditions as hold for VS ete is reduced to $\emptyset$. Consider, for example,

(19) a. $\mathrm{Ki}$ kote Amin ete aster?

what side Amin be now

'Where is Amin now?'

b. $\mathrm{Ki}$ ete sa?

what be that

'What is that?'

c. Ki manyer Moris ti ete lôtâ? (Baker 1972: 126).

what manner Mauritius Past be in the past

'What was Mauritius like in the past?'

(20) a. Amin $\emptyset \mathrm{ki}$ kote aster?

Amin what side now

'Where is Amin now?'

b. Moris ti $\emptyset$ kumâ en paradi (Baker 1972: 126).

Mauritius Past like a paradise

'Mauritius was like a paradise.' 
c. Li nepli $\emptyset$ la.

he no longer there

'He is no longer there.'

d. Sa zâfâ-la ti $\emptyset$ malê. that child-the Past clever

'That child was clever.'

e. Kisâla $\emptyset$ to siperyer?

who your superior

'Who is your superior?'

f. Arlet ti $\emptyset$ ar mwa (Baker 1972: 104).

Arlette Past with me

'Arlette was with me.'

g. Sa later-la $\emptyset$ pu Tôtô Bolo (Baker 1972: 104). that land-the of Uncle Bolo 'That land belongs to Uncle Bolo.'

In equative WH questions, such as (19b) or (20e), ete is optional. This is a direct consequence of the fact that in such questions either the WH constituent or the topic NP can be taken as subject: as has been shown (compare [8] above), VS does not apply when V is directly followed by the subject, but it does when $\mathrm{V}$ is directly followed by the predicate nominal (compare [1a] above). Note that (21b) below would be ungrammatical without ete, precisely because akolad must be subject. As far as I have been able to observe, ete varies with $\emptyset$ precisely along the lines of the VS rule. It seems sensible, therefore, to regard the null morpheme $\emptyset$ as the idiosyncratic syncopated variant of $e t .^{8}$

Having dealt with these details, we must now formulate one obvious restriction to VS. All available data show unambiguously that VS does not apply before an embedded $S$, with or without complementizer, nor before an embedded VP with complementizer, as is shown in (21a)-(21d):

(21) a. Al gete kisála $\emptyset$ sa (*get) (Virahsawmy, ZM).

go see who that

'Go see who that is.'

b. To pa kone ki ete akolad? (*kon) (Virahsawmy, ZM). you not know what be accolade

'Don't you know what an accolade is?'

c. Li ti truve ki mo pa kapav marse (*truv).

he Past see that I not can walk

'He saw that I couldn't walk.'

d. Li pe lite pu dibut lor so propre lipye (*lit).

he Cont. fight for to stand on his own foot

'He is fighting to stand on his own feet.' 
When the verb is followed directly by a predicate adjunct, as in (22a) and (22b), judgments differ. According to Anand Syea, ${ }^{9}$ VS does not apply, but other informants (including Philip Baker) say it does:

(22)

a. Li pe mars/marse tuni.

he Cont. walk naked

'He is walking naked.'

b. $\mathrm{Ki}$ to ti mâz/mâze kri? what you Past eat raw

'What did you eat raw?'

So far the complication is minor and easy to deal with. It means simply that the expression VP-final in (12) must be extended so as also to cover the position immediately preceding an embedded $\mathrm{S}$ or an embedded VP with complementizer, and, at least for those speakers who side with Syea, also the position immediately preceding a predicate adjunct. This new generalization seems to hold pretty well.

Even, so, however, we are not out of trouble yet. There is a problem with bare infinivites, that is, without a complementizer, right after the verb that is up for syncopation. Here we see that in some cases VS does not apply, whereas in the majority of cases it does. Let us first consider some cases where VS does not apply before an embedded bare infinitive: ${ }^{10}$

a. Li fin bliye ferm laport-la (*bliy).

he Perf. forget shut door-the

'He has forgotten to shut the door.'

b. Mo pa oze fer sa $\left({ }^{*} o z\right)$.

I not dare do that

'I dare not do that.'

c. Li ti degaze mâze (*degaz).

he Past hurry eat

'He ate in a hurry.'

d. Gete kumâ li pe asize mâze (*asiz).

look how he Cont. sit eat

'Look how he is sitting there eating.'

e. Li ti dibute pêtir lakaz-la (*?dibut).

he Past stand paint house-the

'He was standing up painting the house.'

f. Person pa forse (pu) mâz dipê (*fors).

nobody not force (for to) eat bread

'Nobody is forced to eat bread.'

It is not always easy to get one's facts straight, especially with creole languages that are energetically kept out of the schools, as is the case with 
MC. One has to take into account a much greater uncertainty about what constitutes 'proper' MC than what is normally found in communities whose language is the officially recognized medium of education and communication. Yet the judgments as given in (23a)-(23f) seem reasonably certain. Then, (23f) could be used both with and without the complementizer $p u$. What interests us here, of course, is the variant without $p u$.

In the majority of cases, however, we see that VS does apply before a bare infinitive:

(24) a. Pa bizê aret mâze (*arete).

not need stop eat

'It's not necessary to stop eating.'

b. Li pa ule ed sarye bagaz-la (*ede).

he not want help carry luggage-the

'He doesn't want to help carry the luggage.'

c. Li res kôtin(ye) ${ }^{11}$ plore (*reste).

he stay continue cry

'He keeps crying.'

d. Li pu vin/al mâze (*vini/*ale).

he FUT come/go eat

'He will come to eat/go eating.'

e. Mo fin tan dir (ki) so papa malad (*tâde).

I Perf. hear say (that) his father ill

'I've heard it said that his father is ill.'

f. Bizê kon rekôpâs lepep (*kone) (Virahsawmy, ZM).

need know reward people

'One must know how to reward people.'

g. Li sey kasyet so kol (*seye). (Virahsawmy, ZM).

he try hide his collar

'He tries to hide his collar.'

h. Li rod tâde (*rode).

he try hear

'He is trying to hear.'

i. Lapli pe komâs tôbe (*komâse).

rain Cont. begin fall

'It is beginning to rain.'

j. Les dres to kostim (*lese).

let iron your suit

'Have your suit ironed.'

k. Mo prefer sorti aster (*prefere).

I prefer go out now

'I prefer to go out now.' 
1. Li fin refiz pey mo saler (*refize).

he Perf. refuse pay my salary

'He has refused to pay my salary.'

m. Zot pu desid ferm labutik-la ${ }^{12}$ (*deside).

they Fut. decide close shop-the

'They will decide to close the shop.'

One should, of course, not be misled by cases like the following:

a. Li kone fer rom ar sa.

he know make rum with that

'He knows that rum is made with that.'13

b. Mo truve tuye kiken.

I see kill someone

'I see that someone is killed.'

where the nonsyncopated verbs kone and truve are followed by an embedded finite object clause without complementizer, a possibility that MC freely allows for. That this is so appears clearly from the grammaticality of (26) and the ungrammaticality of this sentence with the verb syncopated:

(26) Mo ti truve ti tuye kiken (*truv).

I Past see Past kill someone

'I saw that someone was killed.'

since the past tense particle $t i$ can occur only with finite verb forms. ${ }^{14}$

The question now is, how can we account for the difference between (23) and (24) in a principled way? We have the generalization that VS applies postcyclically, after WH fronting but before lower finite subject raising (as in [18] above), in all cases where $\mathrm{V}$ is followed by other material of the same VP except an embedded clause, VP, or, for some speakers, predicate adjunct. If we want to maintain this generalization we must find a principled way of assigning different structures to the sentences of (23) and those of (24), in such a way that the infinitivals of (23) form embedded VPs whereas those of (24) do not and thus make the preceding governing verb VP-internal. This means that we cannot simply impose some uniform standard pattern of infinitival embedding on all these sentences and make the processing dependent on the kind of tree structure associated with that pattern. Some distinction will have to be made, in such a way that the right structural analysis comes about for the cases of (23) and (24). We shall now see how this is naturally achieved, in the theory of semantic syntax, by means of the lexical assignment of rule-induction properties to verbs. 


\section{Predicate raising}

\subsection{Theoretical frame}

Semantic syntax is a language-independent transformational system within the group of VSO and SVO languages, mapping semantic analyses (SA) onto surface structures (SS) and vice versa (though it is usually presented in the 'top-down' format). SAs are of the following general structure:

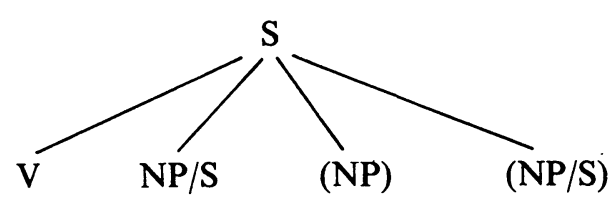

where the first argument after $\mathrm{V}$ is the subject, the second is the (optional) indirect object, and the third is the (optional) direct object. The language of SAs is, furthermore, defined by a number of configurational constraints relating mostly to the possible positions for logical operators such as negation, conjunction, disjunction, quantifiers, modalities, and, in particular, tense/aspect. All such operators are of the category V (predicate). The assumption (based on Reichenbach 1947) is that each finite clause takes two tenses, $t_{1}$ and $t_{2}$, whereas embedded nonfinite clauses have either no tense or just $t_{2}$, depending on the subcategorization features of the governing V. $\mathrm{t}_{1}$ is either Pres or Past, linking up indexically with contextual time; $t_{2}$ is either Sim ('simultaneous') or Prec ('preceding') with respect to $\mathrm{t}_{1}$. (Prec is lexicalized as fin in MC.) The lexical 'filling' of an $\mathrm{S}$ begins with the selection of some $\mathrm{V}$ (predicate). $\mathrm{V}$ is specified in the lexicon for the number and kinds of arguments it can take, its argument structure, which must conform to the schema given in (27). The standard tree structure for a full clause in the language of SAs is thus

(28)

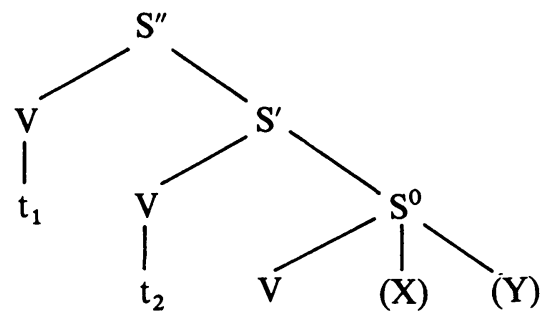

(A superscript attached to an $S$ node indicates the number of tenses contained in the $S$ in question.) 
On the basis of this input a small number of highly restricted cyclic transformational operations can take place, of which the following are relevant for the analysis given here: ${ }^{15}$

a. A V (predicate) can be raised or lowered, but never deleted.

When $\mathrm{V}$ is raised it is adopted (see below) by the next higher V.

When $\mathrm{V}$ is lowered it lands on a specifically defined landing site in the next lower $\mathrm{S}$ or $/ \mathrm{S}$.

b. A subject NP can be raised or deleted, but never lowered.

When NP is raised it takes the place of its own $\mathrm{S}$, the remainder of which shifts one position to the right.

When NP is deleted the whole NP branch is erased without trace.

'Adoption' is the term used for the standard form of adding further material to a categorial node (mostly a $\mathrm{V}$ node). The adopting node puts in a copy above itself, and the adopted material is added as a daughter to the new copy, at the right or the left of the original node (right or left adoption). Right adoption is demonstrated in (30); left adoption runs analogously:

(30) Right adoption

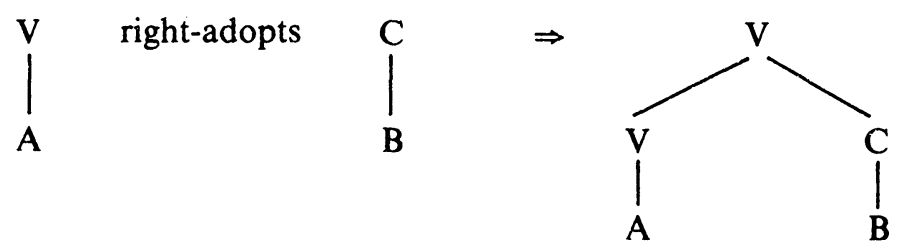

There are, furthermore, a handful of standard effects on trees resulting from the operations as defined in (29a) and (29b):

(31) a. If an $\mathrm{S}$ loses its subject NP (through raising or deletion), it is demoted to the lower category of /S (=VP).

b. If an $\mathbf{S}$ loses its $\mathbf{V}$ through raising, the $\mathbf{S}$ node in question is pruned and all its remaining non- $V$ material is reattached to the next higher $S$ node, at the right of the material already there. If an $\mathrm{S}$ loses its $\mathrm{V}$ through lowering, it stays, unless it is idle.

c. Idle nodes are pruned. (A node $\mathbf{N}$ is idle just in case it directly dominates only one other node $\mathbf{M}$ and $\mathbf{M}$ is of the same labeling as $\mathbf{N}$.) 
d. Raising never affects the categorial status of the raised node. Lowering, which is only possible for $\mathrm{V}$ nodes, usually affects the categorial status of the lowered node, which then acquires a different categorial status (such as adverb, particle, preposition) in its landing site.

This enables us to formulate a few standard transformations, which are specified in the lexicon as being induced by each predicate (V) that takes as one of its admissible arguments an embedded $S^{0}$ or $S^{\prime}$ (an $S^{\prime \prime}$ is impenetrable for cyclic rules: fully tensed Ss are cyclic islands). A rule induced by the $\mathrm{V}$ of some $\mathrm{S}_{\mathrm{n}}$ is activated on the $\mathrm{S}_{\mathrm{n}}$ cycle. The standard transformational rules allowed for by this machinery which are directly relevant to our discussion are those given in (32) (the complete list is only a little longer):

(32) a. Predicate raising (PR): the (right or left) adoption of the lower $\mathrm{V}$ by the governing ${ }^{16} \mathrm{~V}$ that induces $\mathrm{PR}$. The lower $\mathrm{S}$ is pruned and its remaining material is added to the right of the material of the higher S. (PR seems to be restricted to lexical predicates.)

b. Predicate lowering (PL): the lowering of the inducing $\mathrm{V}$ into the next lower $\mathrm{S}$. The proper landing site is defined for each case in each language. (PL is typical for logical or other abstract predicates.)

c. Subject raising (SR): the raising of the subject NP of an argument $S^{0}$ or $S^{\prime}$ to the position of its own $S$, the rest of which shifts one position to the right. This $S$ is demoted to /S (=VP). $\mathrm{SR}$ is induced by the $\mathrm{V}$ governing the $\mathrm{S}$ whose subject is raised.

d. Subject deletion (SD): the deletion of the subject NP of an argument $S^{0}$ or $S^{\prime}$ under conditions of semantic identity with a controlling NP which is either in the higher embedding $\mathrm{S}$ (vertical $S D$ ) or in a parallel argument $S$ (horizontal $S D$ ). The argument $S$ is demoted to /S (=VP). SD is induced by the V governing the $S$ whose subject is deleted.

The general format of these four rules in terms of tree structures is as in (33) (the rules induced are given in angled brackets below the lexical V; subscripts of Ss indicate depth of clause embedding; in all cases $S_{n+1}$ has maximally one tense; $X, Y, Z$ indicate possible further material): 
(33) a. PR:
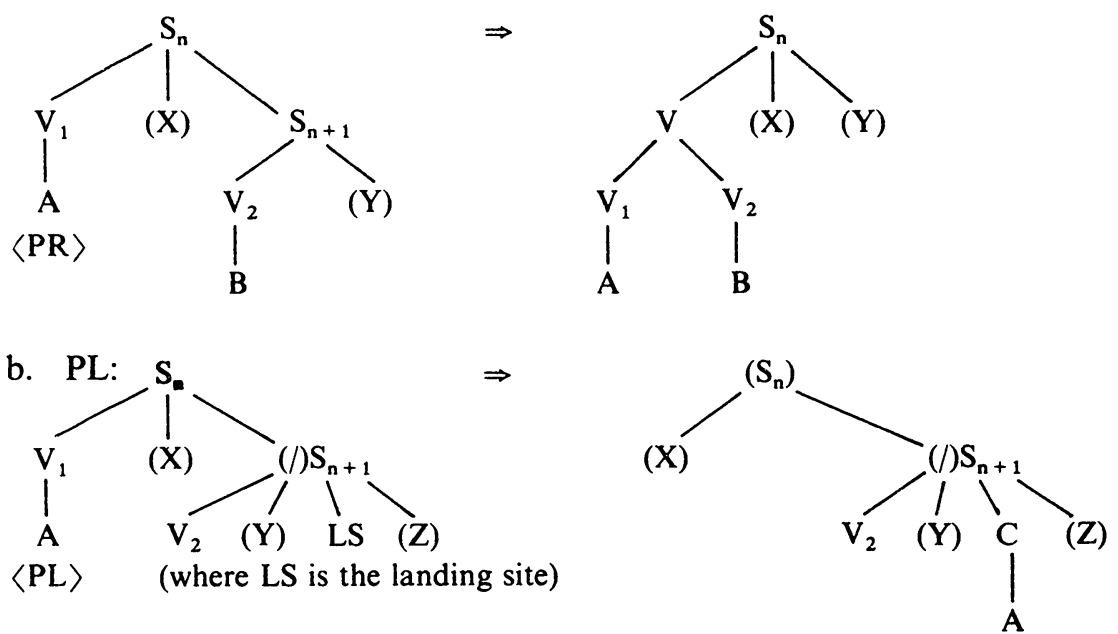

(where $\mathrm{C}$ is the new category assigned to $\mathrm{V}$ )
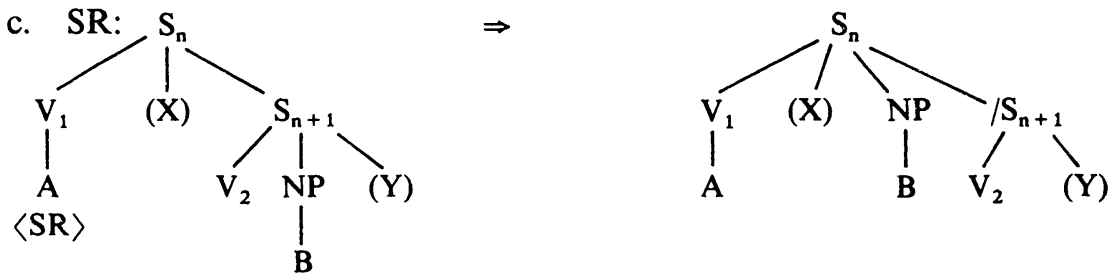

d. Vertical SD:
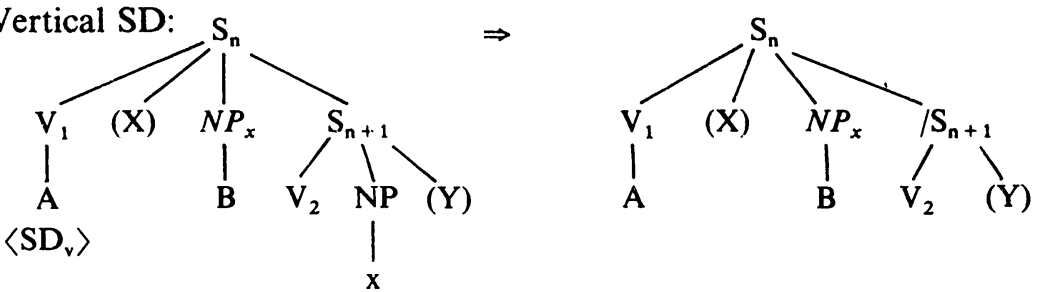

(the controlling $\mathrm{NP}_{\mathrm{x}}$ is italicized)

e. Horizontal SD: ${ }^{17}$
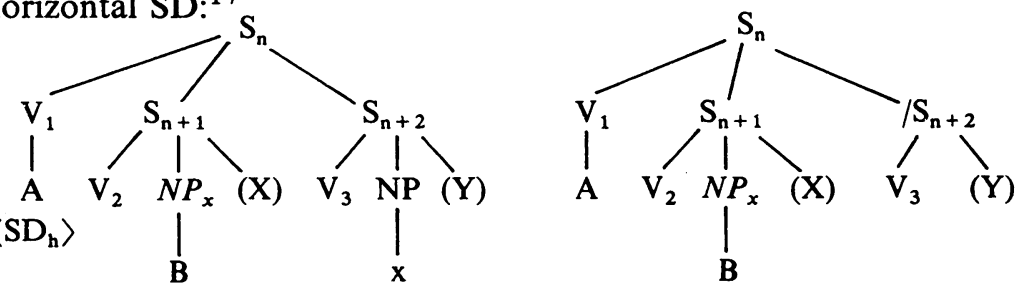
The standard treatment of the tenses in SVO languages is as follows. The lower tense, $t_{2}$ (see [28] above) induces PL (in all cases I know of LS is $V_{2}$, which adopts $t_{2}$ ). The higher tense, $t_{1}$, induces both SR and PL (again onto $\mathrm{V}_{2}$ ). The only difference with VSO languages is then that in these $t_{1}$ does not induce SR, but only PL. To illustrate this tense processing we show what happens to (28) above:

(34)
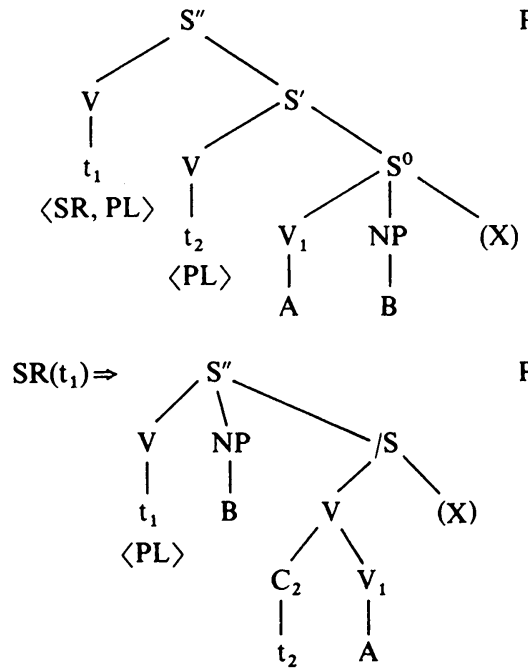

$\mathrm{PL}\left(\mathrm{t}_{2}\right) \Rightarrow$

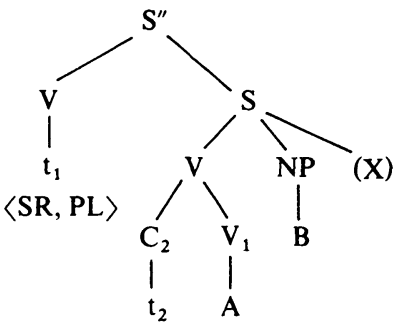

$\operatorname{PL}\left(\mathrm{t}_{1}\right) \Rightarrow$

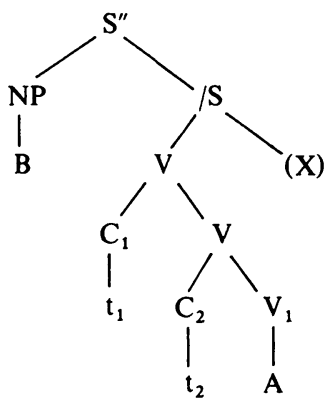

This is how an underlying VSO structure is systematically transformed into the NP-VP structure of SVO languages.

With some extensions, including, for example, the grammar for NPs, this machinery generates essentially the end-cyclic shallow structures of all VSO and SVO languages from semantic analyses. When these shallow structures are subjected to only the obligatory postcyclic rules, the set of canonical sentences for each VSO or SVO language is generated. This establishes a core treatment for the syntax of all languages of the types mentioned. As regards the canonical sentences of each separate language, the differences with other languages are seen to reside (a) in the lexical assignments of rules features, and (b) in the obligatory postcyclic rules. ${ }^{18}$

\subsection{The solution}

In terms of the apparatus sketched in section 2.1 we can now account for the ditterence between the sentences of (23), with nonsyncopated main 
verbs, and those of (24), whose main verbs have been syncopated. The account is based on a judicious assignment of rule induction features to the complement-taking verbs. This amounts in principle to the assignment of PR plus, wherever necessary, $\mathrm{SD}_{\mathrm{v}}$ to the relevant verbs in (24) and all other verbs that behave likewise, but of only $\mathrm{SD}_{\mathrm{v}}$ to the relevant verbs of (23) and their classmates. In order to illustrate this, we shall first derive (23a):

(35)
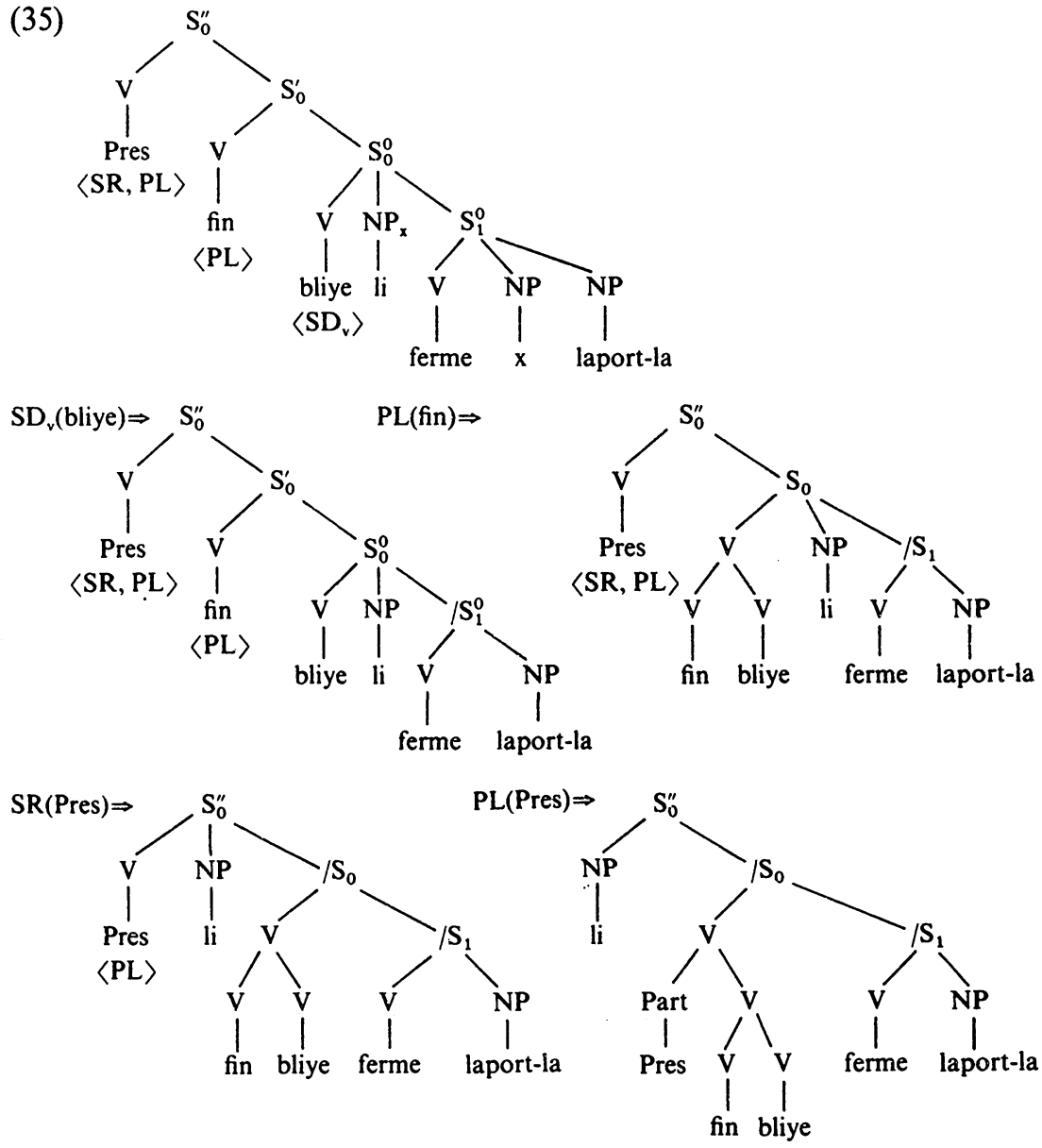

Let Pres be lexicalized as $\emptyset$. Then we see that VS syncopates ferme to ferm, due to it being followed immediately by its object NP laport-la. VS does not apply to bliye, since this verb is immediately followed by the embedded $/ \mathbf{S}_{1}^{0}(=\mathrm{VP})$. 
Analogously, we shall now derive $(24 \mathrm{~g})$ :

(36)

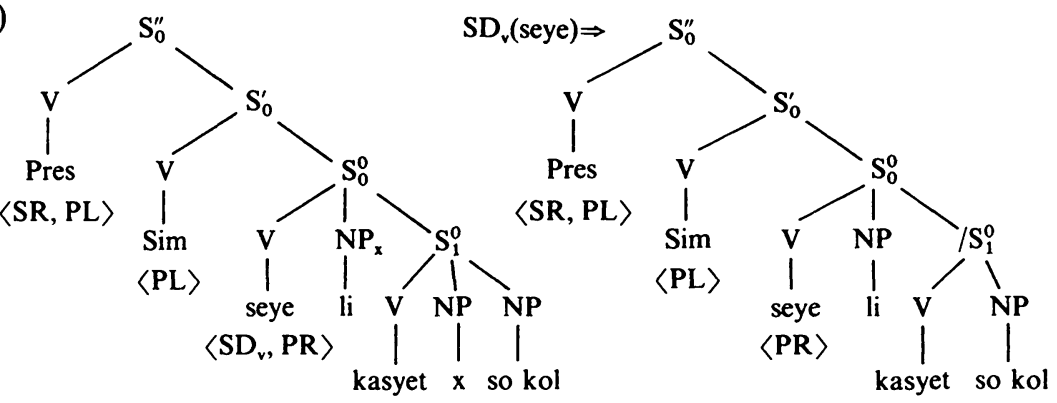

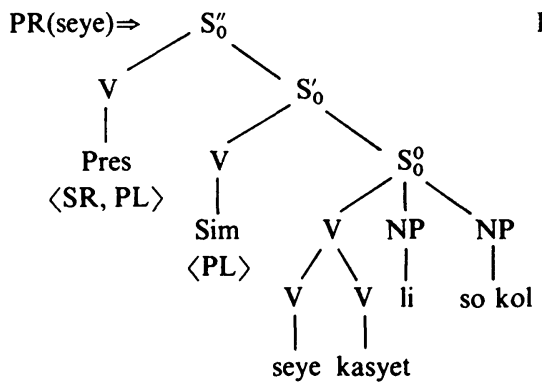
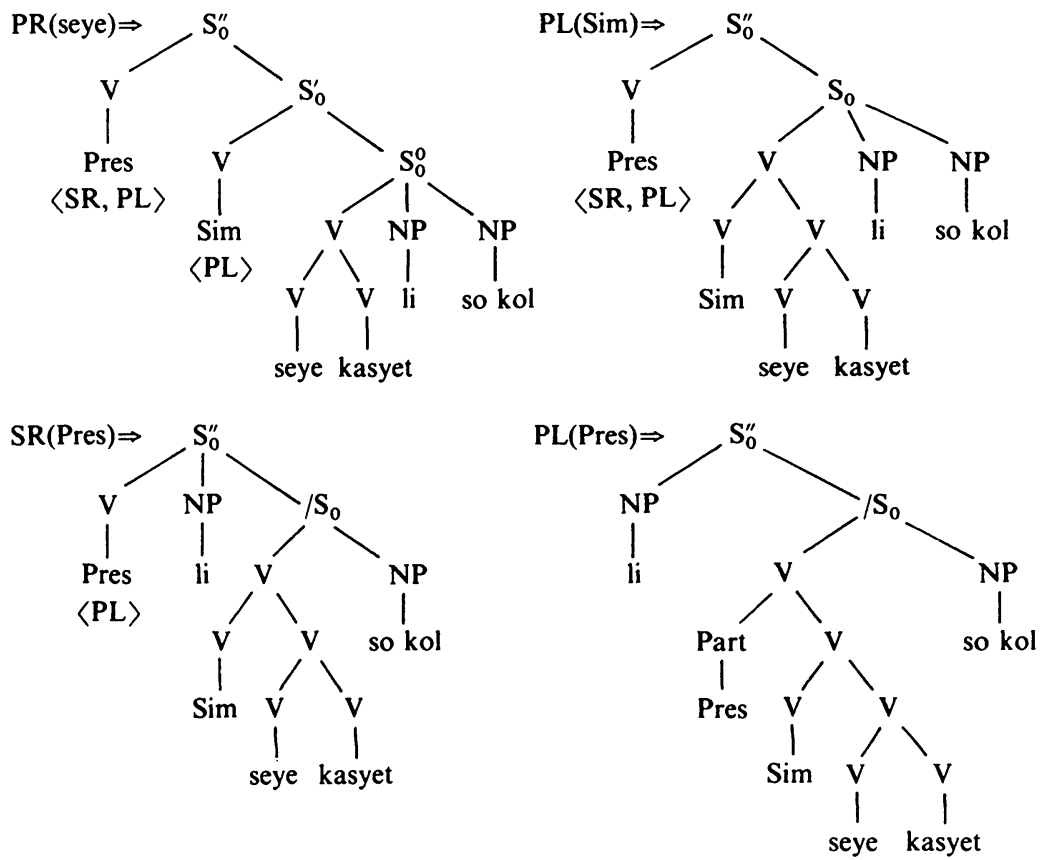

Let $\operatorname{Sim}$ ('simultaneous') be lexicalized as $\emptyset$, just like Pres. We now see that VS must apply to seye, since this verb belongs to the class of syncopators and is VP-internal. VS does not apply to kayset, because this verb is not a syncopator.

We thus decide to assign just the rule-induction feature $\mathrm{SD}_{\mathrm{v}}$ to the verbs

bliye 'forget' asize 'sit' oze 'dare'

dibute 'stand' degaze 'hurry'

forse 'force' 
that is, the relevant verbs of (23), and to all other complement-taking verbs that turn out to behave in the same way. But we assign $\mathrm{SD}_{\mathbf{v}}$ plus PR to the verbs

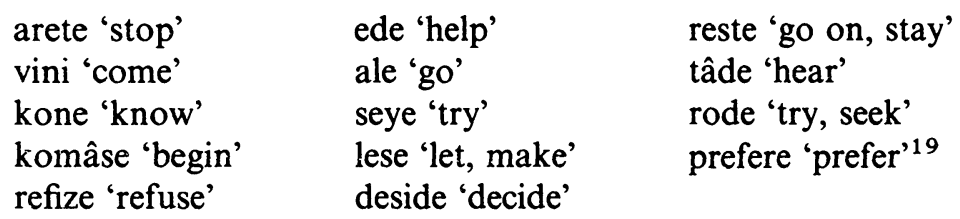

which are the verbs shown in (24), and furthermore to espere 'hope', and, as we shall see, also to fer 'make, cause'. This is, in principle, the reason why VS does not apply in the sentences of (23) but does apply in those of (24).

\subsection{Further details of predicate raising}

2.3.1. Predicate raising in general. Let us now have a closer look at the rule of predicate raising in general, before looking at PR in $M C .^{20}$ It appears that there are languages that have a clear predilection for PR and do not, or hardly, allow for SR. Cases in point are German and Dutch, where PR occurs with a large class of verbs, and where no SR occurs with lexical verbs. On the other hand, there are languages, such as English, where the dominant option is SR, and where PR does not, or hardly, ${ }^{21}$ occur with lower verbs being raised. ${ }^{22}$ French appears to have a preference for PR, which, as is now well known, occurs typically with faire 'make, cause', laisser 'let' (only when the verb is transitive, not when it is ditransitive), and a few other verbs under rather strict limitations. In other cases French seems to limit itself to just $\mathrm{SD}_{\mathbf{v}}$. SR is highly exceptional and is noted by professional language watchers as being marked. ${ }^{23}$ It thus seems that there are SR-oriented and PR-oriented languages. The two rules certainly compete, so to speak, for the same territory in different languages, and sometimes, as in MC (as we shall see in the following subsection), in the same language.

Dutch, as has been said, sticks out as a PR-oriented language, not only because there is no SR in the language, but also because the class of PRinducing verbs is so large: I have so far counted over 40 such verbs (with slight dialectal differences). In fact, one has to search for complementtaking verbs that do not induce $\mathrm{PR}$ (but only $\mathrm{SD}_{\mathrm{v}}$ ), such as the verbs besluiten 'decide' or bevelen 'order', though quite a few verbs take PR optionally (sometimes with a semantic difference). What is interesting in this context is that repeated application of PR to complement Ss with object terms leads to an output structure where all the nouns are shifted 
to one side and all the verbs to the other, with so-called crossing dependencies, as in, for example, ${ }^{24}$

... dat Marie Jan de hond de krant wilde proberen that Marie Jan the dog the newspaper wanted try

te leren laten halen.

to teach let fetch

'... that Marie wanted to try to teach Jan to let the dog fetch the newspaper.'

The derivation of this clause in terms of semantic syntax is as follows (parentheses around rule-induction features indicate the optionality of the rule in question):

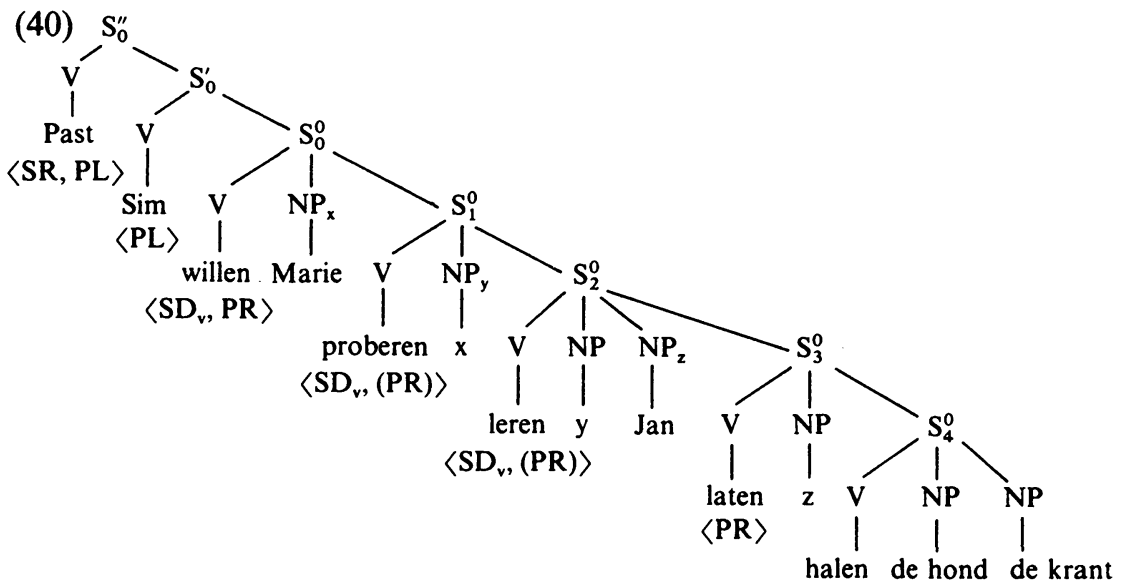

If $\mathrm{PR}$ is applied on all cycles where this is possible, the following shallow structure comes about: ${ }^{25}$

(41)

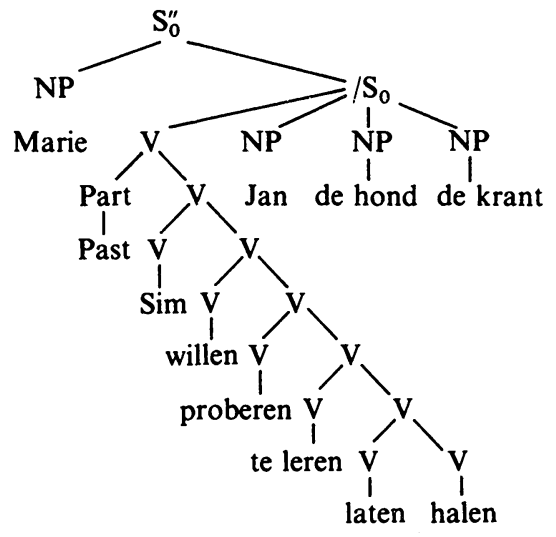


A postcyclic rule of verb final then moves the whole verbal cluster to the far right under the $/ S_{0}$ (that is, VP), but never across an embedded $S$ or VP (note the parallel with the MC rule of VS). This, with the required morphological treatment of the main verb form wilde (the other verbs undergo no change: they are all infinitives) gives us (39), as the reader will easily ascertain for himself. The reader might also care to ascertain that the following semantically equivalent and grammatically correct variants are likewise allowed by the system, according to whether PR is or is not selected for the verbs leren and proberen, for which this rule is optional:

(42) a. ... dat Marie ${ }_{v P}\left[\operatorname{Jan}_{v}\left[\right.\right.$ wilde proberen te leren] ${ }_{v P}[$ de hond de krant $\mathbf{v}[$ te laten halen]]]

b. ... dat Marie ${ }_{\mathrm{vP}}[\mathrm{v} \text { [wilde proberen }]_{\mathrm{vp}}[$ Jan de hond de krant $\mathrm{v}[\mathrm{te}$ leren laten halen]]]

c. ... dat Marie ${ }_{\mathrm{vP}}\left[\mathrm{v}[\text { wilde proberen }]_{\mathrm{VP}}\left[\mathrm{Jan}_{\mathrm{v}}[\text { te leren }]_{\mathrm{vP}}[\mathrm{de}\right.\right.$ hond de krant $v[$ te laten halen]]]]

In (42a) PR has not applied on the leren cycle, with the result that a VP comes about after this verb. (Within each VP the verb or verbal cluster is moved to the far right but never across a VP or S boundary.) In (42b) PR has not applied on the proberen cycle, so that we see a VP after proberen. And in (42c) PR has applied neither on the leren cycle nor on the proberen cycle, so that we have two embedded VPs, one after leren and one after proberen.

Note that German is very much like Dutch in this respect. In fact, for the verbs chosen in (39) the rule features are identical in these two closely related languages. The only important difference between Dutch and German, as regards PR, is the fact that Dutch takes right adoption for PR, whereas German takes left adoption. The result is that the German verbal clusters have an ordering that mirrors the order of their Dutch counterparts. This is demonstrated by the direct translation of (39) into German:

... daß Marie Jan den Hund die Zeitung holen lassen zu ... that Marie Jan the dog the newspaper fetch let to lehren versuchen wollte. teach try wanted

Modulo this difference in the directionality of adoption, German thus has the same variants for (43) as Dutch has for (39), according to whether optional PR has or has not applied.

The purpose of this little exercise in formal grammar is to show how repeated application of $P R$ may lead to structures with quite a number 
of NPs followed or preceded by quite a number of verbs. Especially when the dependencies cross, as in Dutch (due to the inverted directionality in adoption, German does not have crossing dependencies in such cases), such sentences quickly become hard or even impossible to construe: with more than four NPs preceding the verbal cluster, speakers tend to give up. ${ }^{26}$ This means that PR is not at all conducive to what may be called the semantic transparency of the sentences where it applies consecutively to a number of transitive embedded Ss. It is, in fact, deleterious to semantic transparency already in cases where, as a result of PR, the canonical surface word order is disturbed. This happens for example when PR is not preceded by $\mathrm{SD}_{\mathrm{v}}$, so that the lower subject finishes up AFTER its governing verb (assuming that the language in question has no rule like verb final), as in the English sentence (quoted in note 21):

\section{I vp[ v[let go] the line $]$}

In cases as simple as (44) this will not do much harm, but it is not hard to imagine that learners will find a sentence like (45a) much easier to grasp than its ungrammatical equivalent $(45 \mathrm{~b})$ (if such a sentence were part of the English language). The difference is that in (45a) SR has applied twice, whereas in (45b), quite against the rules of English, of course, PR has been made to apply twice, once for make and once for let:

(45) a. I ${ }_{v P}\left[v[\right.$ let $] J o h n{ }_{v P}\left[v[\right.$ make $]$ the student ${ }_{v P}[v[$ leave] the room $\left.]]\right]$

b. I vp[ v[let make leave] John the student the room]

Not only does (45b) have crossing dependencies, the canonical English SVO word order is gravely disturbed.

One may wonder why languages (such as Dutch) resort to rules like PR, which complicate comprehension rather than help it. I cannot pretend that I have a ready answer to this question. We cannot do much more, at this moment, than establish and recognize the fact that some natural languages behave this way. Yet it may be observed, in defence of PR, that the formation of a verbal cluster (' $\mathrm{V}$ island') is a natural first step toward its lexicalization. It was in this context that McCawley (1968) introduced PR, and the appropriateness of this origin is borne out by cases like English $\mathrm{v}$ [let go], or Dutch $\mathrm{v}$ [leren kennen] 'make the acquaintance of', whose origins are clearly in PR structures but whose meanings are no longer entirely derivable compositionally from their component parts but have acquired idiosyncratic elements. From here it is but a small step to surmise that a verb like show is a lexicalization of a 'prelexical' PR structure v[let see], as was proposed in McCawley's early papers on 
prelexical syntax. It is too early to make any definite statments on these and related issues. Nevertheless one may, perhaps, speculate that there is something in human cognition, not as yet spelled out with sufficient clarity, which favors the formation of $\mathrm{V}$ islands for the expression of newly formed complex concepts. But even if this were to appear to be the case, it remains hard to understand what allows languages like Dutch or German to make such an extravagant use of this particular, apparently counterproductive, syntactic process. For those linguists who, as the present author does, prefer to think that functionality is one of the underlying rationales for the ways structures are handled in grammars of natural languages, there is clearly a problem here. We cannot hope to solve this problem now, but we can point to the way that $\mathrm{PR}$ is incorporated into the grammar of MC. This will then show that MC, though making use of this counterproductive-looking rule, manages not to have the semantic transparency of its sentences impaired.

2.3.2. Predicate raising in $M C$. In the light of the general thesis that creole languages are characterized by a tendency to maximize semantic transparency (so that the acquisition process for young children as well as adult newcomers to the language community is maximally facilitated; see Seuren and Wekker 1986), it is surprising to find the rule of PR in a creole language like MC. PR is not the kind of rule one would expect in a creole language. Yet, if the condition given above, in (12), for the application of verb syncopation is accepted as being correct, it is difficult to avoid the assumption that MC does have the rule of PR. How else can we explain the fact that we find full verbs in (23) and syncopated verbs in (24) above?

There are other indications as well that point to the conclusion that MC does indeed have PR. Consider the following sentences:

(46) a. Mo fin tan dir (ki) so papa malad (*tâde). $(=[24 \mathrm{e}])$

I Perf. hear say (that) his father ill

'I've heard it said that his father is ill.'

b. Mo fin truv tuy kiken.

I Perf. see kill someone

'I have seen someone being killed.'

c. Les dres to kostim. $(=[24 \mathrm{j}])$

let iron your suit

'Have your suit ironed.'

d. Serzâ-la pa ule fer vin en dokter sergeant-the not want make come a doctor (Virahsawmy. Li).

'The sergeant does not want to call a doctor.' 
The first thing that strikes the linguist is the position of the grammatical subject of the lower verb after, not before, its verb in all four cases, unlike their English translations, where the lower subject stands before its verb. Against this one might observe that in (46a)-(46c) the final NP is not the subject but the object of the lower verb, whose subject has remained unspecified and is not represented by any lexical material. One might then say that the object stands in its proper position, postverbally.

This is, however, not correct, for the following reason, which strengthens the case for PR in MC on independent grounds. First, it is possible to add an agent phrase to (46a)-(46c), such as ar li 'by him/her', which shows that we have a real passive in these cases. (As has been said in connection with [15]-[17] above, MC does have a passive without passive morphology, but with a fully developed agent phrase.) The final NP in (46b) and (46c) and the clause in (46a) must thus be taken to be the grammatical subject of the lower verb, which has been passivized. Grammatical subjects of passive sentences normally stand in the normal position for subjects, that is, before VP, and thus before V. It is possible to postpose the subject, whether or not the sentence is passive, as we saw in (25a) and (25b) above, where the subjects of the embedded finite clauses (both passive) are postposed. So we might accept that the lower verbs in (46a)-(46c) are passivized and that, therefore, the following NPs are grammatical subjects, but we might still propose that these subjects have been postposed in virtue of whatever rule or process allows subjects to be postposed. This proposal, however, is again immediately defeated: postposed subjects fall outside the VP, as is shown by the nonsyncopated verb form tuye in (25b), and likewise in the question sentences (8a) and (8b): postposed subjects do not make the preceding governing verb take VS. But what we see in (46b) and (46c) is syncopated, not full, verb forms: tuy and dres, respectively. (The form dir in [46a] tells us nothing in this respect since it does not belong to the class of syncopators.) Note the striking difference with (25b): Mo truve tuye kiken, where the full form tuye occurs, clearly because there we have a finite clause with postposed subject. The question, therefore, arises: how can the syncopated forms tuy and dres in (46b) and (46c), respectively, be explained. And the answer is, obviously, that these are cases of PR, so that the underlying subject of the lower verb lands in object position under higher $\mathrm{S}$, as is demonstrated in (47) for (46b): 

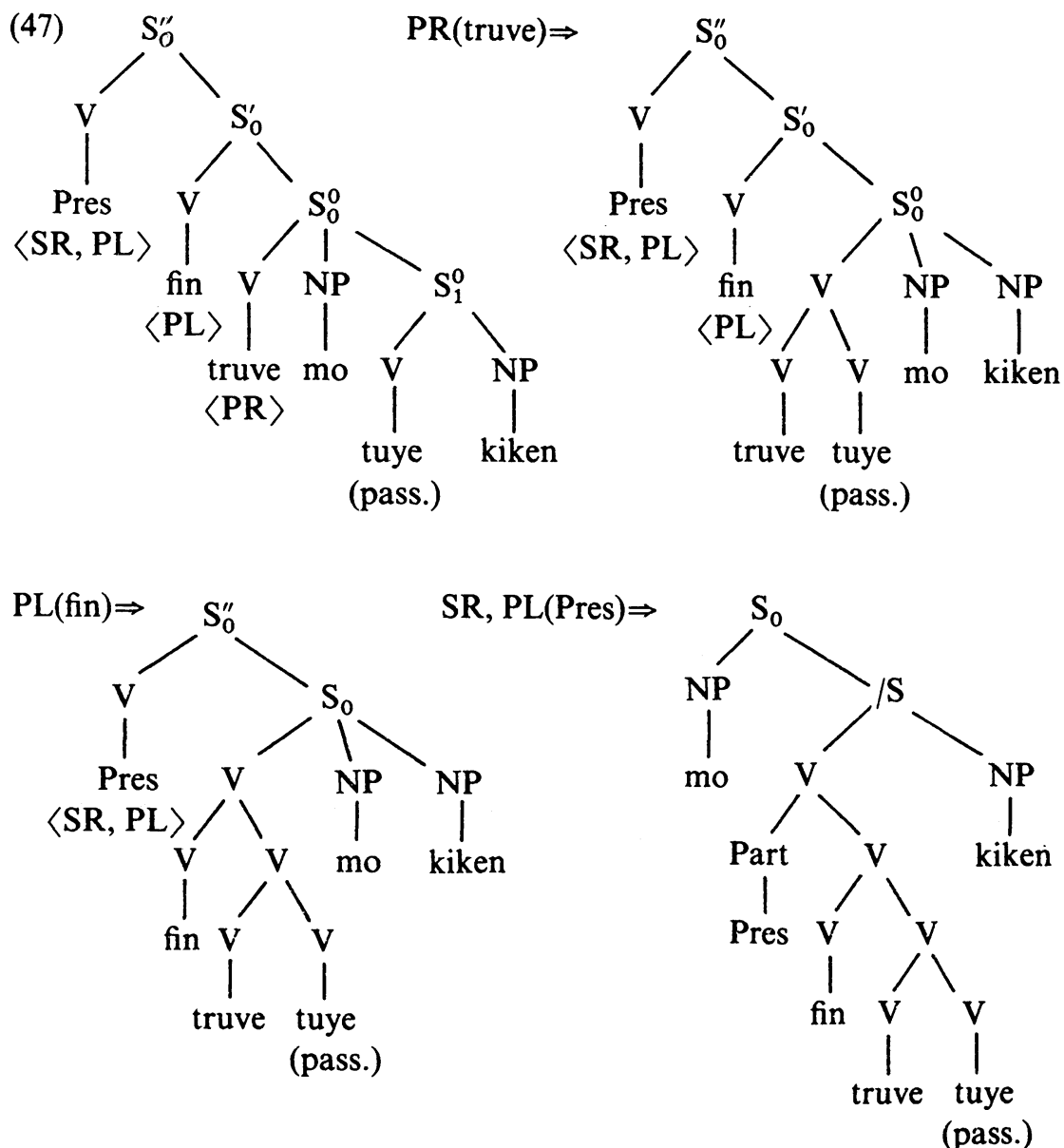

This final structure shows that VS must apply to truve and tuye. Kiken now has the position of object to the $\mathrm{V}$ cluster and is not a postposed subject. This strongly confirms the PR analysis.

So, we conclude that in (46a)-(46d) the original subjects of the lower verbs end up in the object position of the higher $\mathrm{S}$, the 'governing' $\mathrm{V}$ now being the whole new $\mathrm{V}$ island. This may be considered just a little bad for semantic transparency, but not in any serious way. However, even in these cases some trouble is stirring just below the surface. This shows up when we consider (46d).

For (46d) no separate analysis seems required: en dokter is clearly the semantic subject of $\operatorname{vin}(i)$ and is treated exactly as the grammatical subjects of (46a)-(46c) are. Yet (46d) can also be expressed as (48), which is 
even preferred by some speakers. This variant is not possible for (46a)(46c), but it is for $(46 \mathrm{~d})$ :

(48) Serzâ-la pa ule fer en dokter vini.

where the semantic subject of vini precedes its governing verb, as it does in ordinary main clauses, and where vini is not syncopated. This sentence cannot be derived by means of PR; it requires SR on fer, even though fer has the rule-induction feature PR, and not $S R$ :

(49)

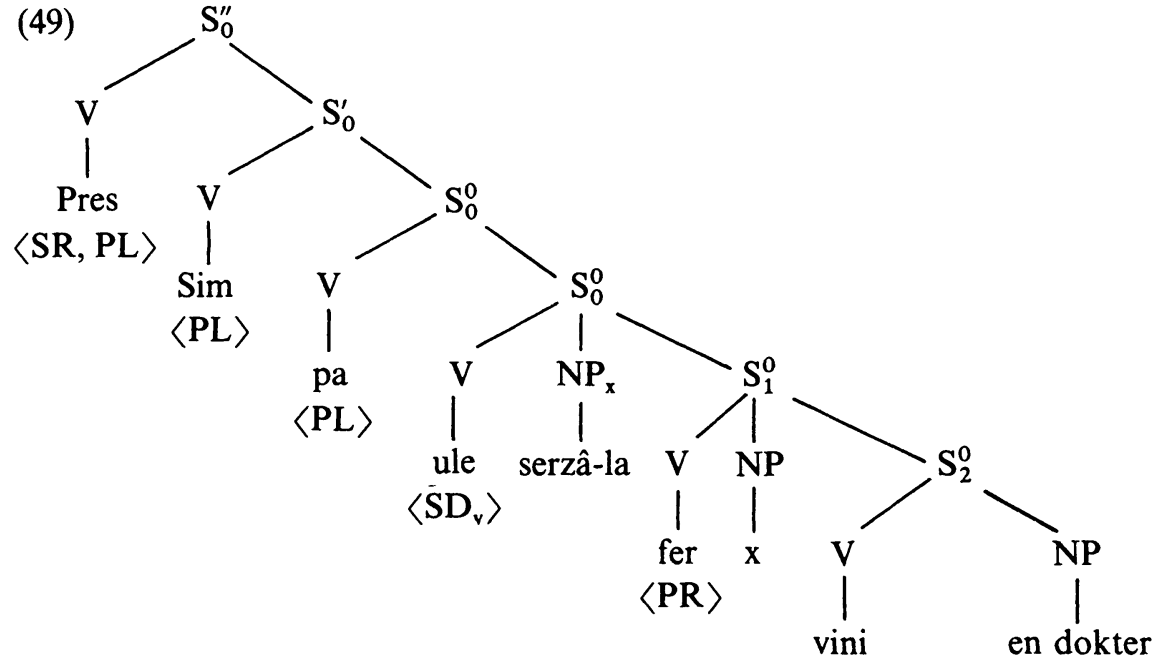

If, instead of PR, we apply SR on the fer cycle, we get the shallow structure as given in (50) (the negation $p a$ is lowered to the position left of the lower $\mathrm{V}$ ule and is recategorized as particle):

(50)

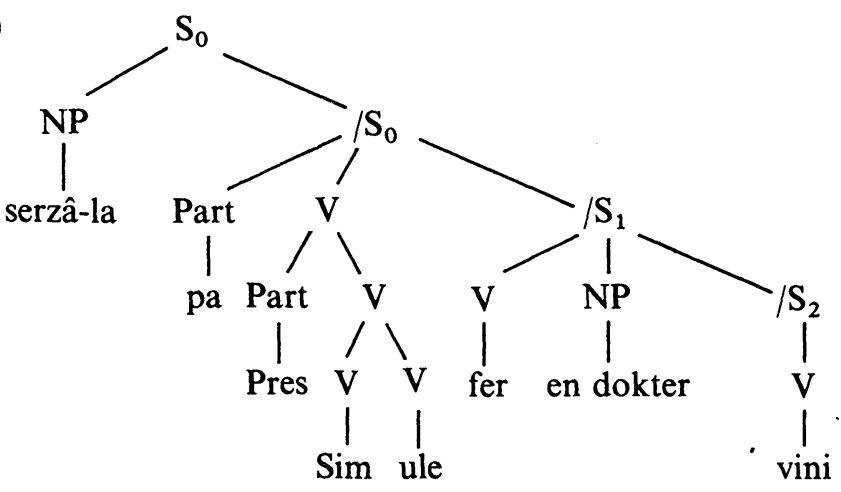


This shallow structure gives the correct constituent order together with the correct branching structure: two embedded VPs, $/ \mathbf{S}_{2}$ as a result of SR on fer, with en dokter in object position to fer, and $/ \mathrm{S}_{1}$ as a result of $\mathrm{SD}_{\mathbf{v}}$ on ule.

However, given the rule-induction feature 'PR' assigned to fer, we should not be allowed to apply SR instead. Yet this happens more often, not only in (48) but also in cases like the following:
a. Mokuzê pu fer mwa gagn en bô travay. my cousin Fut. make me get a good job
'My cousin will get me a good job.'
b. Mo fin tan so papa dir sa nuvel-la I Perf. hear his father say that news-the 'I've heard his father tell that news.'
c. To pu les mwa dres mo kostim. you Fut. let me iron my suit 'You will let me iron my suit.'

The position as well as the oblique case of the lower subject $m w a$, and furthermore the syncopated forms tan and les make it clear that SR has applied on the verbs fer, tâde, and lese, and not PR, even though these verbs are marked in the lexicon for PR. In fact, if PR is applied in these sentences, resulting in, respectively,

(52) a. *Mo kuzê pu fer gagn mwa en bô travay.

b. *Mo fin tan dir so pap sa nuvel-la.

c. *To pu les dres mwa mo kostim.

what we get are grossly ungrammatical sentences.

The reader will meanwhile have begun to wonder what is going on here. What does it mean to assign the rule-induction feature PR to a verb in MC? When precisely does PR apply, and when is it replaced by SR? Let us have a closer look now. We will then see that there are strict conditions for the actual application of PR for the verbs that are lexically marked for this rule. PR marking for a verb means, in MC, that PR must apply in some structures, may apply in others, and is excluded and replaced by $S R$ in yet other kinds of structure. We will also see that there appears to be a general rationale behind these restrictions: they ensure that semantic transparency is preserved despite the presence of the cyclic rule of PR in MC.

It is fairly obvious that $\mathrm{PR}$ is blocked when the embedded $\mathrm{S}$ has more than one argument. In all three cases of (51) (and [52]) the lower S has two NP arguments, a subject and an object. Apparently, this is a sufficient condition for PR to be automatically replaced by SR. This is confirmed 
by the following observation. We have seen that the agent phrase with a passive does not have the status of argument to the (passive) verb: it falls outside the VP. The indirect object, on the contrary, clearly does have argument status, whether it is internal, and thus without preposition, or external, that is, with preposition. It so happens that the preposition most used in current $\mathrm{MC}$ for the passive agent phrase is identical to the preposition used for the external dative: ar. We now observe that both of the following two sentences are grammatical, but they differ in meaning: ${ }^{27}$
a. Mo fin tan dir sa nuvel-la ar so papa.
I Perf. hear say that news-the by his father
'I have heard that news being told by his father.'
b. Mo fin tan sa nuvel-la dir ar so papa.
I Perf hear that news-the say to his father
'I have heard that news being told to his father.'

In (53a) PR has applied, as we see from the order of the constituents, and the passive lower verb dir is followed by just one argument, its grammatical subject sa nuvel-la. The agent phrase that follows does not have argument status. In (53b), on the other hand, SR has applied, and the passive lower verb is accompanied by two nominal arguments, the grammatical subject sa nuvel-la and the indirect object ar so papa. My informants did not hesitate to assign the different meanings in just the way they are in (53). This suggests that PR IS AUTOMATICALLY REPLACED BY SR WHEN THE EMBEDDED S HAS MORE THAN ONE PHONOLOGICALLY OVERT NOMINAL ARGUMENT TERM. It is easily seen that this prevents the occurrence of long sequences of NPs following long sequences of verbs with crossing dependencies when PR is applied on consecutive cycles, as in the horrible Dutch sentence (39) above.

In fact, this condition is more general: when, as a result of $\mathrm{PR}$, more than one nominal argument follows the raised verb, the result is filtered out as ungrammatical, regardless of whether the two (or more) NPs are arguments to the same verb or to different verbs. Thus, if we want to say in MC 'He doesn't want to help us carry the luggage' (compare [24b] above, which is the same sentence but without the 'us'), we cannot apply PR, due to the extra NP $u s$, which is object to help and controls the deletion of the subject of carry. Thus, (54a) is the proper expression for this meaning, but not the ungrammatical (54b):

(54) a. Li pa ule ed nu sarye bagaz-la.

b. *Li pa ule ed sarye nu bagaz-la.

In (54a) only $\mathrm{SD}_{\mathrm{v}}$ has taken place, and no PR. SR is not possible, of course, since the lower subject has been deleted and thus cannot be raised. 
We can, therefore, formulate the following filtering constraint for PR application in $\mathrm{MC}$ :

(55) a. If PR were to result in more than one NP following the raised V, PR does not apply.

If the lower $\mathrm{S}$ has an overt subject, SR applies instead.

Significantly, PR is not blocked when the lower $\mathrm{S}$ is transitive but the subject has been removed by $\mathrm{SD}_{\mathrm{v}}$, as for example in $(24 \mathrm{~g}),(241)$, and (24m) above. In fact, PR is obligatory in such cases. It is generally obligatory when there is no overt lower subject, not only when this is due to $\mathrm{SD}_{\mathrm{v}}$ but also, for example, when the lower subject is nonspecific, as in (24a) and (24f). Provided constraint (55a) is not violated, PR is obligatory (when the verb in question is marked for it) whenever there is no overt lower subject. Interestingly, passive sentences are treated as having no overt subject, since PR is clearly obligatory when the lower $\mathrm{V}$ is passive (and constraint [55a] is not violated). What counts, therefore, is whether there is an overt SEMANTIC lower subject. This enables us to formulate a further constraint on PR application in MC:

(55) b. PR is obligatory for PR verbs when the lower (tenseless) $\mathrm{S}$ lacks an overt semantic subject, provided constraint (55a) is not violated.

This leaves us with the cases where the lower $\mathbf{S}$ does have an overt semantic subject but no further nominal arguments, and where PR will not result in a violation of (55a) on account of already present higher NP arguments. We saw an example in (46d) above. The constraints (55a) and (55b) neither block nor impose PR in such cases. We have already seen that PR cannot be declared obligatory, because (48), where SR has applied, is also a correct way of saying the same. Careful observation of the material shows that in such cases PR is indeed optional, but there are grades of preference: when the lower subject of the intransitive $S$ is pronominal, as in (56a) and (56b), PR is either favored or on a par with SR. But the 'heavier' the lower subject, the less favored PR becomes. Thus, (57a) $(=[46 \mathrm{~d}])$ is still quite acceptable, in fact, it is attested in the literature, but $(57 \mathrm{~b})(=[48])$ is at least equally acceptable. But $(58 \mathrm{a})$ is rejected quite clearly by informants, in favor of $(58 \mathrm{~b})$ :

(56) a. Serzâ-la pa ule fer vin twa.

b. Serzâ-la pa ule fer twa vini.

'The sergeant doesn't want to call you.'

(57) a. Serzâ-la pa ule fer vin en dokter.

b. Serzâ-la pa ule fer en dokter vini.

'The sergeant does not want to call a doctor.' 
a. *Li pa ule fer vin sa bug ki ena en grâ he not want make come that man who have a large lakaz-la. ${ }^{28}$ house-the

b. Li pa ule fer sa bug ki ena en grâ lakaz-la vini. 'He doesn't want to call that man who owns a large house.'

Interestingly, however, (58b) is not considered ideal either by informants. They much prefer

(59) Li pa ule fer vini sa bug ki ena en grâ lakaz-la.

where the full form vini shows that PR has not applied. What has happened here is simple postposition of a heavy NP. As with subject postposition, as demonstrated in ( $8 \mathrm{a}),(8 \mathrm{~b})$, and $(25 \mathrm{~b})$ above, the postposed NP falls outside the VP and thus does not cause application of VS to any preceding $\mathrm{V}$.

Summarizing, we can thus formulate the following modus of application of, or constraint on, PR in MC:

(60) a. PR must not result in more than one NP after the raised V.

b. $P R$ is obligatory when the lower $S$ lacks an overt semantic subject, provided $(60 \mathrm{a})$ is not violated.

c. $\mathrm{PR}$ is optional when the lower $\mathrm{S}$ is intransitive with a not-tooheavy overt semantic subject NP, provided (60a) is not violated.

d. Whenever PR does not apply and there is an overt lower subject NP, SR applies instead of PR.

The net result is, clearly, that the canonical subject-verb-object order of constituents in unmarked main clauses is never disturbed by PR, except, optionally, when the lower embedded $S$ is intransitive with a not-tooheavy overt subject.

This is a gratifying result for linguists who seek a functional explanation for linguistic rules and structures, since constraint (60), which is based on an analysis that provides a tailor-made fit with the observed facts, is seen to protect the language from semantic opacity. And semantic opacity is something that creole languages, again for good functional reasons, have an unusually strong aversion to. On the other hand, linguists who like mathematically elegant and formally rectilinear grammatical systems will not like this result at all, since it looks almost absurdly contorted in terms of formal systems. It does seem, however, that the facts of MC make it very difficult to get around the analysis presented here. To the extent that the analysis given above is factually and formally correct and not in competition with possible alternative and equally correct analyses, the 
position of strict formalism is weakened, and the more ecologically oriented approach to language analysis is reinforced. ${ }^{29}$ At the same time, however, if we accept the analysis provided here we are forced to incorporate into our general theory of grammar the formal possibility of certain specified rule alternations under certain specified conditions, a feature of grammars that had so far not come to light. The combined rules of VS and PR in Mauritian Creole thus appear to be of prime theoretical interest for the general theory of grammar.

Received 20 November 1988

University of Nijmegen

Revised version received

20 September 1989

\section{Notes}

1. I am grateful to Philip Baker, Anand Syea, and some anonymous referees, who read an earlier draft of this paper and pointed out a few inconsistencies, inaccuracies, and also real flaws. Correspondence address: Instituut voor Taalfilosofie, KUN, Postbus 9108, 6500 HK Nijmegen, The Netherlands.

2. I have taken quite a few examples from Virahsawmy (1967), which was his Linguistics Diploma dissertation at Edinburgh University, and also from other nonlinguistic but literary works, mainly theater plays, by the same author. The reason is obvious: we have here a linguistically sophisticated fine-tuned native speaker of $\mathrm{MC}$, who has, moreover, been very productive as a dramatic writer in his native Creole. The titles and years of the plays from which example sentences have been taken are given in the references.

3. Compare, for example, the different positions of early in the following English sentences:

(i) He got up early in London.

(ii) He got to London early.

Given the age-old notion of adverbials as a morphological repository for all kinds of semantically heterogeneous elements, it is hardly surprising to find that the syntactic behavior of adverbials sometimes still reflects their semantic origin.

4. The final $-l a$ rounds off the relative clause: the MC definite article is postposed and spans the whole NP, including any relative clause.

5. Philip Baker informs me (personal communication) that he has tested the following little dialogue on a number of Mauritians of diverse backgrounds, and they all agree that kumâs/e requires its long form in the one case and its short form in the other:

A: $\mathrm{Ki}$ fer to prese kumsa?

'Why are you in such a hurry?'

B: Dallas kumâse wit er trât.

'Dallas starts at 8.30.'

A: Nô, ta. To fer erer. Li kumâs nev er.

'No it doesn't. You're wrong. It starts at 9.00.' 
My guess is that this is so on account of the fact that the second occurrence picks up the first and so establishes a 'closer link'. Needless to say, this notion is in need of further clarification!

6. The lifting of the subject from an embedded finite object clause into the main clause, where it becomes a quasi cbject is by no means exceptional. It is comnion in French, Italian, Modern Greek, and no doubt many more languages. Compare the Modern Greek (taken from a song):
(i) Thélo ton ánthropo na échi kardiá.
I want the (Acc.) man that he has heart
'I want a man to have a heart.'

7. Compare Labov (1969) for copula deletion in New York Black English; Seuren (1986a) for the same in Sranan. Corne (Baker and Corne 1982: 34-35) rejects the idea of an underlying copula and selective deletion by a syntactic rule. His rejection, however, is based on the misconception that if material is deleted under certain conditions while it stays under other conditions, the deletion cases should somehow be 'less basic' than the cases where no deletion takes place. There is, however, no such connotation associated with deletion rules at all.

8. Ete should not be confused with the verb ena, which means either 'there is/are' or 'have'. Ena is never syncopated or deleted.

9. In a paper read at the Amsterdam Workshop on Creole Morphology, 30-31 March 1989.

10. Anand Syea (personal communication) informs me that in (23c), (23d), and (23e) an aspect marker can occur before the embedded infinitive, as in Zot pe asize pe zwe cart 'they are sitting playing cards.'

11. The verb kotinye is a syncopator for some speakers but not for others, due to the nasalized vowel (see above). In the speech of those speakers for whom this verb is a syncopator one gets the shortened form, kôtin or kôtiy.

12. An alternative way of expressing the same meaning is with the full verb deside and the complementizer pu: Zot pu deside pu ferm labutik-la. This is, however, not the construction at issue here.

13. This example is due to Anand Syea (private correspondence).

14. Under certain conditions MC allows for sentences or clauses with a postposed subject, as in (8a) and (8b) or the object clauses of (25) and (26). In addition, MC allows for impersonal sentences without any overt subject, as in $\mathrm{Pa}$ van sigaret isi 'One doesn't sell cigarettes here'; lit. 'not-sell-cigarettes-here', where the syncopated form van (full form: vâde) proves the object status of sigaret. Compare also (24a) and (24f) above. (Note that MC never drops its subject pronouns.)

15. What is given in (29a) and (29b) is pretty well exhaustive, but for the operation of superimposition, whereby two parallel and largely identical Ss are collapsed into one $\mathrm{S}$, with splitting branches where the differences are. This process is a central component of conjunction reduction, which is not at issue here.

16. The relation 'govern' is reserved for lexical (and not logical or abstract) predicates and their arguments: a predicate governs its (nominal or sentential) arguments at SA level. In other words, a predicate $\mathbf{P}$ governs a node $\mathbf{N}$ in an SA structure just in case $\mathbf{P}$ is lexical and $\mathbf{P}$ and $\mathbf{N}$ command each other.

17. Horizontal SD is not directly relevant to this paper, though vertical SD is. Horizontal SD is found, for example, in English sentences like

(i) He fell asleep while eating.

analyzed at SA level as 
(ii) ${ }_{s}\left[v[\text { while }]_{s}\left[\mathrm{v}[\text { fall asleep }]_{N P}\left[\text { he } e_{x}\right]\right]_{s}\left[v_{v}[\text { eat }]_{N P}[x]\right]\right]$

Through $\mathrm{SD}_{\mathrm{h}}$ this becomes

(iii) $s\left[v[\text { while }]_{s}\left[\mathrm{v}[\text { fall asleep }]_{N P}[\text { he }]\right]_{/ s}[\mathrm{v}[\right.$ eat $\left.]]\right]$

Object incorporation then makes ${ }_{v}\left[\right.$ while] adopt the object argument ${ }_{/ s}$ [v[eat]], and PL makes this new complex $\mathrm{V}$ land at the far right in $\mathrm{s}_{\mathrm{v}}[$ [fall asleep] $\mathrm{NP}[$ [he] $]$, to give

(iv) $\mathrm{s}\left[\mathrm{v}[\text { fall asleep }]_{\mathrm{NP}}\left[\right.\right.$ he] $\mathrm{PP}_{\mathrm{P}}[\mathrm{w}$ [wile] $\mathrm{v}[$ eat $]]$.

18. A full account of this theory of syntax is in preparation (Seuren forthcoming).

19. Syea (personal communication) wonders why VS applies with the negation $p a$ intervening between the higher and the lower verb, as in: Zot prefer $/{ }^{*}$ prefere pa fer sa 'they prefer NOT to do that'. The answer is that in semantic syntax the negation is a sentential operator in the semantic input structure: $\left.{ }_{s}\left[v[\text { prefere }]_{N P}\left[z_{x} t_{x}\right]_{s}[\mathrm{pa}]_{s}\left[v[\mathrm{fer}]_{N P}[x]_{N P}[\mathrm{sa}]\right]\right]\right]$. On its cycle, $p a$ is lowered onto $f e r$, thus giving the $\mathrm{V}$ island ${ }_{\mathrm{v}}\left[\mathrm{part}[\mathrm{pa}]_{\mathrm{V}}[\mathrm{fer}]\right]$. This island is then adopted by prefere at the appropriate cycle. The result thus does not differ structurally from what is found without the negation $p a$.

20. The fist extensive study of PR is Seuren (1972), where data from French, Dutch, German, and a few more exotic languages are analyzed. Evers (1975) discusses PR for Dutch and German.

21. A rare case of $\mathbf{P R}$ in English, whereby a lower verb is raised, is the idiosyncratic construction let go, as in I let go the line.

22. $P R$ is frequent in English in cases where the raised predicate is not a verb but an adjective (as in $I$ cut open the parcel) or an adverbial or prepositional particle (as in He put forward an idea).

23. Thus, Grevisse (1969: 1064, $\S 1008 \mathrm{~b})$ notes the deviant character of a phrase like

(i) ... ces quelques mots qu'il fait Nisus adresser à son Euryale ... (Gide, Journal 1942-1949: 306).

where both the position and the case of Nisus show that SR has been applied instead of $P R$, the reason being no doubt that ordinary PR would have given rise to the stylistically awkward

(ii) ... ces quelques mots qu'il fait adresser à Nisus à son Euryale ...

24. It is customary to present Dutch sentences in their subordinate form, not as main clauses, the reason being that in main clauses verb clusters are split up in such a way that the underlying syntactic processes are masked.

25. Note that proberen 'try' has the extra rule feature that it dispenses a functionally empty 'te to the following infinitive. Leren 'teach, learn' does so only when PR is not applied.

26. Remarkably, the more rapidly such sentences are pronounced and the better integrated they are in the context running, the better the chances of getting the meaning right of these, otherwise monstrous, products. This fact may have interesting consequences for psycholinguistic theories of sentence comprehension.

27. Baker rejects (53a) as it stands but accepts it if sa nuvel-la is replaced by a clause.

28. As regards the final $-l a$, see note 4 .

29. Compare Seuren (1986b) on the two 'philosophies' in language analysis, formalism and ecologism, and the arguments for a judicious blend of the two.

\section{References}

Baissac, C. (1880). Étude sur le patois créole maurtcten. Nancy: Berger-Levrault.

Baker, P. (1972). Kreol. A Description of Mauritian Creole. London: Hurst. 
-, and Corne, C. (1982). Isle de France Creole. Affinities and Origins. Ann Arbor, MI: Karoma.

-, and Hookoomsing, V.Y. (1987). Diksyoner kreol morisyen. Dictionary of Mauritian Creole. Dictionnaire du créole mauricien. Paris: L'Harmattan.

Corne, C. (1980). A re-evaluation of the predicate in Ile-de-France Creole. In Generative Studies on Creole Languages, P. Muysken (ed.), 103-124. Dordrecht: Foris.

Evers, A. (1975). The transformational cycle in Dutch and German. Unpublished Ph.D. dissertation, Utrecht.

Grevisse, M. (1969). Le bon usage. Grammaire française avec des remarques sur la langue française d'aujourd'hui, 9th ed. Paris: Duculot-Geuthner.

Labov, W. (1969). Contraction, deletion, and inherent variability of the English copula. Language 45 (4), 715-762.

McCawley, J. D. (1968). Lexical insertion in a transformational grammar without deep structure. In Papers from the Fourth Regional Meeting, Chicago Linguistic Society, 71-80. Chicago: Linguistics Department, University of Chicago.

Reichenbach, H. (1947). Elements of Symbolic Logic. London: Macmillan.

Seuren, P. A. M. (1972). Predicate raising and dative in French and sundry languages. Unpublished manuscript, Magdalen College, Oxford/L.A.U.T., Trier.

-(1986a). Adjectives as adjectives in Sranan. A reply to Sebba. Journal of Pidgin and Creole Languages 1 (1), 123-134.

-(1986b). Formal theory and the ecology of language. Theoretical Linguistics $13(1 / 2)$, $1-18$.

-(forthcoming). The Principles of Semantic Syntax.

-, and Wekker, H. C. (1986). Semantic transparency as a factor in Creole genesis. In Substrata versus Universals in Creole Genesis, P. Muysken and N. Smith (eds.), 57-70. Creole Library 1. Amsterdam: Benjamins.

Stein, P. (1984). Kreolisch und Französisch. Tübingen: Niemeyer.

Virahsawmy, D. (1967). Towards a re-evaluation of Mauritian Creole. Unpublished diploma dissertation in Applied Linguistics, Edinburgh University.

-(1981). Zeneral Makbef (ZM) (theater play).

-(1982). Li (theater play). 